\title{
Headline and Core Inflation: An Empirical Analysis Based on the ECB Survey of Professional Forecasters
}

\author{
M. C. Ramos-Herrera ${ }^{1,2} \&$ S. Sosvilla-Rivero ${ }^{3}$
}

Quantifying individual expectations has become a very important topic in economics, both for academic researchers and policymakers. One of the most relevant advantages of collecting probabilistic expectations is that the quantitative answers can be used to compare predictions across different agents and time, as well as to analyse their consistency.

The Survey of Professional Forecasters (SPF) conducted by the European Central Bank (ECB) offers expectations about real economic growth, inflation and unemploy- ment rates. In this case, we focus on point and probability distribution forecasts for headline and core inflation rates. Since 1999, this SPF has been conducted quarterly. This survey collects responses from financial and other institutions from around the European Union. It is usually based on approximately 75 professional forecasters with an average of 60 respondents for each round. It is subject to revisions during the survey, adapting to different circumstances. These panellists usually update their forecasts following data releases or other events (such as the financial crisis) and some of them may also update because of significant shocks.

First of all, the headline inflation measures the rate of change in prices of all goods and services in an economy over a period of time. Nevertheless, this kind of inflation is not adjusted for seasonality or for the often volatile elements of food and energy prices. This is the reason why we also consider core inflation; to overcome these

* M. C. Ramos-Herrera madelram@cunef.edu

1 Department of Economics and History, Colegio Universitario de Estudios Financieros (CUNEF), C/ Leonardo Prieto Castro, 28040 Madrid, Spain

2 University Complutense of Madrid, Campus de Somosaguas, 28223 Madrid, Spain

3 Department of Economics, University Complutense of Madrid, Campus de Somosaguas, 28223 Madrid, Spain 
disadvantages. Headline inflation is more useful for households in the sense that it measures changes in the cost of living, however core inflation is more useful for central banks because is less volatile and, furthermore, it shows the effects of supply and demand on gross domestic product.

In order to evaluate forecasting performance of the ECB SPF panel regarding the inflation expectations, we consider the root mean square error (RMSE) and the Theil inequality coefficient. Analyzing the headline inflation, the RMSE is high and increases with the time horizon, mainly from 15 months ahead. In the same vein, Theil's inequality coefficient is far from zero, indicating that economic agents make errors in their predictions and worsen prediction quality as we move away along the time horizon. Our findings suggest that the predictive ability is much higher for core inflation than for headline inflation.

Our results provide sufficient empirical evidence to confirm that predictions of these economic agents are better than those from a random walk. The reason to analyse the accuracy of the direction of changes is because some important papers point out the relevance of doing well for investors and policymakers (e.g., Altavilla and De Grauwe, Applied Economics, 2010; Bergmeier et al., Computational Statistics and Data Analysis, 2014).

To check the robustness of the accuracy of the ECB's predictions, we test the hypothesis that the panel forecasts are optimal predictors of future headline and core inflation rates. Following the Grant and Thomas (Economic Letters, 1999) method, we test whether these panellists made unbiased and efficient predictions considering the observed inflation rate for any time horizon. Our results suggest that the rational expectations hypothesis is not fulfilled, but that the "weak form of rationality" is verified in any time horizon.

To ensure that expectations are rational, one necessary requirement is consistency, but this requirement is weaker than rationality. The reason is that there is no requirement that the prediction process match the stochastic process generating the actual series. Following Froot and Ito (Journal of International Money and Finance, 1989), consis- tency of expectations built at the same moment in time dominate if we obtain the same result when comparing expectation about the inflation rate for the entire time period with the expectations about inflation rate changes during shorter time periods. Our results indicate that short-term expectations are consistent with long-term expectations. This issue has important implications for inflation stabilisation and quantitative risk assess- ments (for recent discussions Ball and Mazumder, Brookings Papers on Economic Activity, 2011; Coibion and Gorodnichenko, American Economic Journal of Macroeco- nomics, 2015; and Blanchard, Economics Policy Brief, 2016). 
